\title{
Light-emitting diode effects on combined decellularization of tracheae. A novel approach to obtain biological scaffolds ${ }^{1}$
}

\author{
Thaiane Cristine Evaristo ${ }^{\mathrm{I}}$, Flávia Cilene Maciel da CruzAlves ${ }^{\mathrm{II}}$, Andrei Moroz ${ }^{\mathrm{III}}$, Woner Mion ${ }^{\mathrm{IV}}$, Michele Janegitz Acorci- \\ Valériov, Sérgio Luis Felisbino $^{\mathrm{VI}}$, Rosana Rossi-Ferreira ${ }^{\mathrm{VII}}$, Raul Lopes Ruiz Júnior ${ }^{\mathrm{VIII}}$, Elenice Deffune ${ }^{\mathrm{IX}}$
}

\section{DOI: $h$ ttp://dx.doi.org/10.1590/S0102-86502014000800002}

${ }^{\mathrm{I}} \mathrm{MsC}$, Fellow PhD degree, Postgraduate Program in General Basis of Surgery, Department of Surgery and Orthopedy, Medical School, Paulista State University (UNESP), Botucatu-SP, Brazil. Design, intellectual and scientific content of the study; acquisition, analysis and interpretation of data; manuscript writing.

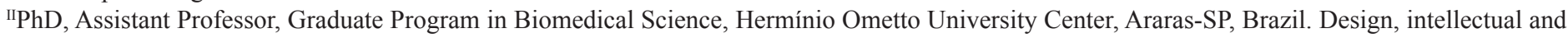
scientific content of the study; acquisition analysis and interpretation of data; manuscript writing.

IIIPhD, Assistant Professor, Department of Bioprocess and Biotechnology, School of Pharmaceutical Sciences, UNESP, Araraquara-SP, Brazil. Intellectual and scientific content of the study, analysis and interpretation of data, responsible for English language, manuscript writing.

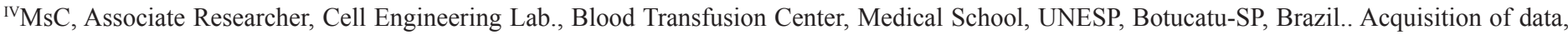
LED irradiation of the tracheae.

${ }^{\mathrm{v}} \mathrm{PhD}$, Associate Professor, Department of Health Science, Paulista University (UNIP), Bauru-SP, Brazil. Analysis and interpretation of data, manuscript writing.

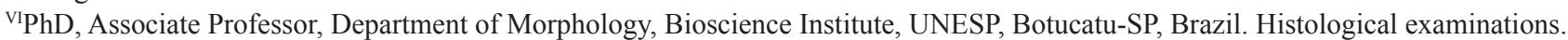

${ }^{V I I} \mathrm{PhD}$, Assistant Professor, Department of Science Biology, Faculty of Science, UNESP, Bauru-SP, Brazil. Manuscript writing, critical revision.

${ }^{\mathrm{VIII}} \mathrm{PhD}$, Assistant Professor, Department of Surgery and Orthopedy, Medical School, UNESP, Botucatu-SP, Brazil. Conception, intellectual and scientific content of the study, critical revision.

${ }^{\mathrm{IX}} \mathrm{PhD}$, Assistant Professor, Department of Urology, Medical School, UNESP, Botucatu-SP, Brazil. Conception, design, intellectual and scientific content of the study, manuscript writing, critical revision, final approval of the version to be published.

\section{ABSTRACT}

PURPOSE: To obtain a decellularized tracheal scaffold associating traditional approaches with the novel light-emitting diode (LED) proposal.

METHODS: This study was performed with New Zealand adult rabbits weighing 3.0 - $4.0 \mathrm{~kg}$. Different protocols (22) were used combining physical (agitation and LED irradiation), chemical (SDS and Triton X-100 detergents), and enzymatic methods (DNase and RNase).

RESULTS: Generally, the cells surrounding soft tissues were successfully removed, but none protocol removed cells from the tracheal cartilage. However, longer protocols were more effective. The cost-benefits relation of the enzymatic processes was not favorable. It was possible to find out that the cartilaginous tissue submitted to the irradiation with LED 630nm and $475 \mathrm{~nm}$ showed an increased number of gaps without cells, but several cells were observed to be still present.

CONCLUSION: The light-emitting diode is a promising tool for decellularization of soft tissues.

Key words: Tissue Engineering. Biocompatible Materials. Quantum Dots. Trachea. Rabbits. 


\section{Introduction}

Tracheal lesions whose length is more than 50\% (around $6 \mathrm{~cm}$ ) in adults and a third of the trachea in small children require curative treatment ${ }^{1-8}$. In many cases, endoluminal therapies followed by surgical procedures are required, resulting in high costs to healthcare systems ${ }^{4,9}$. Failures in repairing such lesions often occur and there aren't any suitable tracheal replacements yet ${ }^{10}$ as these still cause lots of complications such as migration and displacement, degradation and failure in materials, chronic bacterial infection, obstruction by exuberant granulation tissue, stenosis, necrosis, anastomotic failure, hemorrhage due to erosion of blood vessels, need for immunosuppression for life, lack of donor sources, and lack of vascularization and epithelialization ${ }^{4}$.

The biological scaffolds from decellularized organs and tissues have been widely used in pre-clinical studies with animals and in clinical applications in humans. ${ }^{11}$ There are some benefits in using these natural materials ${ }^{12}$, such asbiocompatibility and feasibility to be implanted. However it is necessary to guarantee the decellularization in order to avoid an immunologic response in the host $\mathrm{t}^{13}$, while preserving the remaining extracellular matrix ${ }^{11}$. The physical methods such as freezing, direct pressure, sonication, and agitation disrupt the cell membranes and release their content, favoring the following washing process for the removal of the cell content; nonetheless, these methods usually prove inefficient to reach a full decellularization process, so they should be combined with other methods, such as the chemical ones ${ }^{11}$.

Nonionic detergents have been widely used in decellularization protocols due to their fairly mild effects on tissue structures; triton X-100 is the principal nonionic detergent used in decellularization protocols ${ }^{11}$. The most commonly used ionic detergents are sodium dodecyl sulfate (SDS), sodium deoxycholate and triton $\mathrm{X}-200^{11}$. Even though these detergents have been employed in such processes, it is well accepted that trace amounts of DNA and RNA may remain in the decellularized tissue $^{11}$. Therefore, enzymatic treatment with DNases and RNases are required, leading to high $\operatorname{costs}^{1}$, which has encouraged us to search for alternative solutions.

In this sense, this paper focuses at the use of Light Emitting Diode (LED), a semiconductor device that emits light, as a decellularization agent ${ }^{14-16}$. Even though a cell is usually able to overcome small disturbances of the redox balance, larger-scale disturbances may be lethal to the cells ${ }^{17-19}$, such the apoptosis caused by oxidative stress resulting from LED irradiation ${ }^{17}$. Our research group has been interested in suitable scaffolds for tissue engineering for a long time $\mathrm{e}^{12,20,21}$. This paper describes different techniques of cell removal from tracheae as a proposed three dimensional scaffold, by associating traditional approaches with the novel LED proposal.

\section{Methods}

\section{Animals and housing conditions}

The use of such animals was approved by the Ethics Committee on Animal Experimentation, in accordance with the ethical principles adopted by the Brazilian College of Animal Experimentation, protocol number 751. This study was performed with $22 \mathrm{New}$ Zealand adult rabbits weighing $3.0-4.0 \mathrm{~kg}$. The rabbits were maintained in a controlled ambient and received standard pellet food and water ad libitum.

Briefly, the animals were anesthetized with intramuscular injection of ketamine and xylazine ${ }^{22-24}$. After trichotomy, antisepsis and isolation by sterile fields in the anterior neck, a medium cervicotomy was performed taking into account the skin and subcutaneous cellular tissue. With the aid of retractors, the trachea was exposed from the larynx until the thorax entrance. After the transection of the trachea at $1 \mathrm{~cm}$ from the larynx and $1 \mathrm{~cm}$ from the thorax entrance, the retro tracheal structures were detached, and the animals were sacrificed with a lethal intravenous injection of pentobarbital. ${ }^{25}$

\section{Decellularization protocols}

The 22 obtained tracheae were used for22 different decellularization protocols. All the protocols, were submitted to 180 rpm agitation at $\mathrm{C} 24$ Incubatorshaker (New BrunswickScientific ${ }^{\mathrm{TM}}$ ) at $37^{\circ} \mathrm{C}$. The mechanical agitation was used simultaneously with chemical treatments in order to aid cell lysis and the removal of cell debris ${ }^{11}$. The basal solution of the protocols was $0.02 \%$ EDTA, $1 \%$ antibiotic-antimycotic in $10 \mathrm{ml}$ of phosphate buffered saline solution $^{13}$. The control tracheae were submitted to agitation in basal solutions only.

\section{First set of decellularization protocols (traditional methods)}

The first set of decellularization protocols was developed based on the findings of Elder et al. ${ }^{13}$. The tracheae used were freshly collected, and physical (agitation in basal solution), chemical (2\% SDS, and 2\% triton X-100) and enzymatic methods (type I DNaseand RNase) were associated. No LED was employed in this set of protocols. The enzymatic solutions had $0.5 \mathrm{mg} / \mathrm{mL}$ DNase 
Type I, and $50 \mathrm{mg} / \mathrm{mL}$ RNase ${ }^{13}$. Each protocol was performed for $8 \mathrm{~h}$ and $24 \mathrm{~h}$ to analyze the influence of decellularization time (Figure 1). After such treatments, the tracheae were washed for $2 \mathrm{~h}$ in phosphate buffered saline solution under agitation at $37^{\circ} \mathrm{C}^{13}$, submitted to routine histological processing, stained with hematoxylin and eosin (H\&E) and analyzed at a microscope (Axiostar $^{\circledR}$, Zeiss $^{\mathrm{TM}}$, Germany), as described elsewhere ${ }^{12}$.

\section{Second set of decellularization protocols (LED based methods)}

In the second set of protocols, physical methods (agitation in basal solution), chemical methods (2\% SDS and $2 \%$ triton $\mathrm{X}-100$ ) and LED were associated. The tracheae were submitted to a single nonionizing electromagnetic irradiation with LED on continuous mode with $475 \mathrm{~nm}$ or $630 \mathrm{~nm}$ wavelengths with a dose of $15 \mathrm{~J} / \mathrm{cm}^{2}$ at a total exposure of 10 minutes. Following LED exposure, tracheae were exposed to chemical action with SDS or Triton-X 100 (Figure 2). After such treatments, the tracheae were washed during $2 \mathrm{~h}$ in phosphate buffered saline solution under agitation at $37^{\circ} \mathrm{C}^{13}$, prepared to the histological analysis, as described ${ }^{12}$.

\begin{tabular}{|c|c|c|c|c|c|c|c|c|c|c|c|}
\hline \multicolumn{2}{|c|}{ Sample } & 1 & 2 & 3 & 4 & 5 & 6 & 7 & 8 & 9 & 10 \\
\hline $\begin{array}{l}\text { Phisical } \\
\text { Methods }\end{array}$ & Agitation & & & & & & & & & & \\
\hline \multirow{2}{*}{$\begin{array}{l}\text { Chemical } \\
\text { Methods }\end{array}$} & $2 \%$ SDS & & & & & & & & & & \\
\hline & $\begin{array}{c}2 \% \text { Triton } \\
\text { X-100 }\end{array}$ & & & & & & & & & & \\
\hline $\begin{array}{l}\text { Enzymatic } \\
\text { Methods }\end{array}$ & $\begin{array}{c}\text { Dnase } \\
\text { 1/RNase }\end{array}$ & & & & & & & & & & \\
\hline \multirow[t]{2}{*}{ Time } & 8 hours & & & & & & & & & & \\
\hline & 24 hours & & & & & & & & & & \\
\hline
\end{tabular}

FIGURE 1 - First set of decellularization protocols. Different physical methods (agitation) and chemical methods (2\% SDS and 2\% triton x100) were associated, with or without an extra enzymatic method. Each protocol was performed for $8 \mathrm{~h}$ and $24 \mathrm{~h}$ to analyze the influence of decellularization time. Light gray boxes refer to control of reactions (1 and 2); dark gray boxes refer to the employed protocols (3 to 10). Painted boxes represent methods that were employed during these protocols.

\begin{tabular}{|c|c|c|c|c|c|c|c|c|c|c|c|c|c|}
\hline \multicolumn{2}{|c|}{ Sample } & 1 & 2 & 3 & 4 & 5 & 6 & 7 & 8 & 9 & 10 & 11 & 12 \\
\hline $\begin{array}{l}\text { Phisical } \\
\text { Methods }\end{array}$ & Agitation & & & & & & & & & & & & \\
\hline \multirow{2}{*}{$\begin{array}{l}\text { Chemical } \\
\text { Methods }\end{array}$} & $2 \% \operatorname{SDS}$ & & & & & & & & & & & & \\
\hline & $\begin{array}{l}2 \% \text { Triton } \\
\quad \text { X-100 }\end{array}$ & & & & & & & & & & & & \\
\hline \multirow[t]{2}{*}{ LED } & $\begin{array}{c}475 \mathrm{~nm} \\
\text { LED }\end{array}$ & & & & & & & & & & & & \\
\hline & $\begin{array}{c}\text { 630nm } \\
\text { LED }\end{array}$ & & & & & & & & & & & & \\
\hline \multirow[t]{2}{*}{ Time } & 8 hours & & & & & & & & & & & & \\
\hline & 24 hours & & & & & & & & & & & & \\
\hline
\end{tabular}

FIGURE 2 - Second set of decellularization protocols. Different physical methods (agitation) and chemical methods (2\% SDS and 2\% triton x100) were associated, with or without a single nonionizing electromagnetic irradiation with LED. Each protocol was performed for $8 \mathrm{~h}$ and $24 \mathrm{~h}$ to analyze the influence of decellularization time. Light gray boxes refer to control of reactions $(1,2,7,8)$; dark gray boxes refer to the employed protocols $(3$ to 6 and 9 to 12). Painted boxes represent methods that were employed during these protocols. 


\section{Results}

\section{Decellularization protocols - Gross morphology}

No matter the diversity of the protocols, the tracheal segments got opaque, pearl-colored, harder to the touch, and non-friable after the chemical treatments (Figure 3B). The tracheae treated with $2 \%$ SDS detergent presented a characteristic not identified in the tracheae treated with $2 \%$ triton $\mathrm{X}-100$. Systematically, the tracheae treated with SDS got harder at the end of the treatments, which determined a semi-circular (C-shaped) presentation (Figure 3C), when compared to the tracheae treated with Triton-X 100 (Figure 3D).
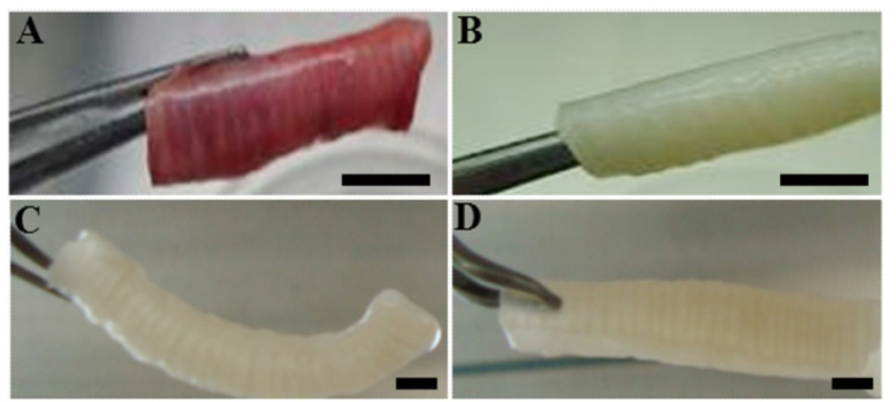

FIGURE 3 - Macroscopical characteristics of the rabbits' tracheal segment. (A) Tracheal segment after surgically removed. No decellularization protocols were employed. (B) Tracheal segment after decellularization treatments. Note that no matter the diversity of the protocols, the tracheal segments got opaque, pearl-colored, harder to the touch, and non-friable after the chemical treatments. (C) Tracheal segment treated with $2 \%$ SDS. The tracheae treated with SDS got harder at the end of the treatments, which determined a semi-circular (C-shaped) presentation. (D) Tracheal segment treated with $2 \%$ triton $\mathrm{x} 100$. The tracheae treated with triton detergent did not present the $\mathrm{C}$-shaped characteristic identified in the tracheae treated with SDS. Scale Bar $=1 \mathrm{~cm}$.

\section{First set of decellularization protocols (traditional methods) - Histology assessment}

The first set of protocols aimed at identifying the contribution of the different detergents in the presence or absence of enzymes under the action of time. There was an internal disruption of the cartilage matrix, but the chondrocytes nuclei remained inside the cartilage lacunae. Not even longer treatment exposure $(24 \mathrm{~h})$ completely removed the nuclei inside the inner cartilage tissue (Figure 4B,D,F,H). However, the cells naturally present at the fibrous perichondrium were successfully removed (Figure 4C).
$8 \mathrm{~h}$
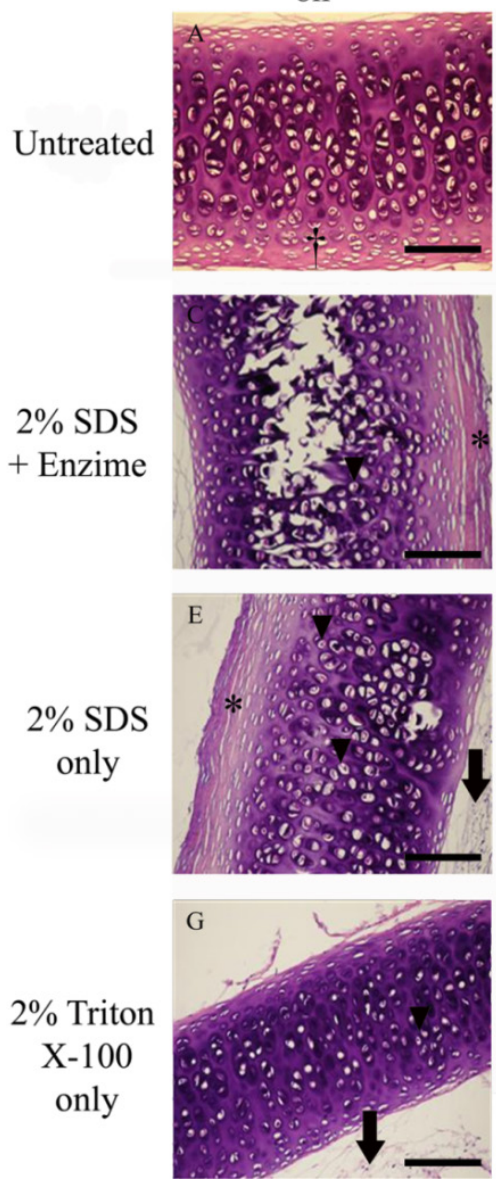

$24 \mathrm{~h}$
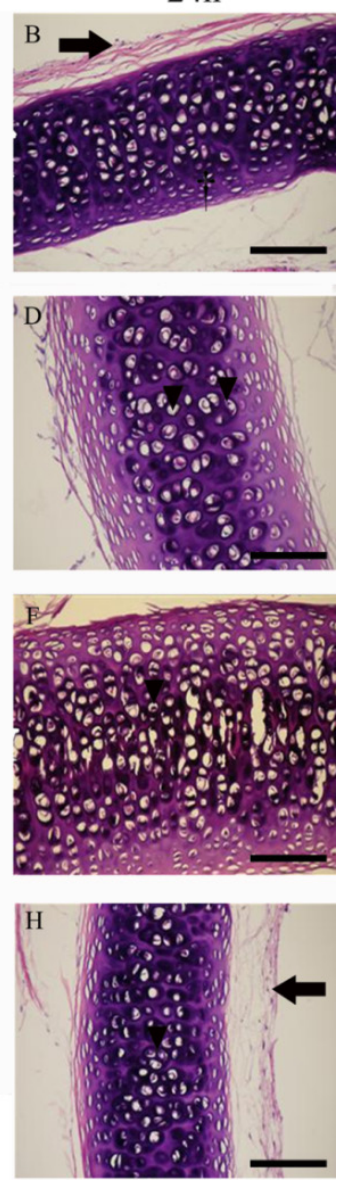

FIGURE 4 - Histological sections of the tracheal rings after the first set of decellularization protocols. The tracheas were submitted to the decellularization protocols, fixed in $10 \%$ buffered formaldehyde, embedded in Paraplast ${ }^{\mathrm{TM}}$, sectioned at a microtome and stained with H\&E. All sections were analyzed at x20 zoom. (A) Untreated tracheal segment were submitted to agitation in basal solutions only during $8 \mathrm{~h}$. (B) Untreated tracheal segment were submitted to agitation in basal solutions only during $24 \mathrm{~h}$. (C) Tracheal segment treated with $2 \%$ SDS and enzyme during $8 \mathrm{~h}$. White spaces inside the cartilage matrix can be visualized due to the histological processing artifact. (D) Tracheal segment treated with 2\% SDS and enzyme during $24 \mathrm{~h}$. (E) Tracheal segment treated with $2 \%$ SDS without enzyme during $8 \mathrm{~h}$. (F) Tracheal segment treated with $2 \%$ SDS without enzyme during $24 \mathrm{~h}$. (G) Tracheal segment treated with $2 \%$ triton $\times 100$ without enzyme during $8 \mathrm{~h}$. (H) Tracheal segment treated with $2 \%$ triton $\mathrm{x} 100$ without enzyme during $24 \mathrm{~h}$. All scale bars $=100 \mu \mathrm{m}$. Morphological aspects: (*) Perichondrial area after decellularization. Note that the decellularization protocols remove all nuclei in this area. $(\dagger)$ Cellular perichondrium of the untreated trachea. Note the normal morphological aspects of the perichondrium. ( $\downarrow$ ) Fibrous perichondrium. Note the presence of fibroblasts nuclei and well-organized and thick type I collagen fibers on the untreated trachea and remaining nuclei at the triton and SDS treated trachea. $(\boldsymbol{\nabla})$ Hyaline cartilage area with the presence of remaining nuclei due to dense extracellular matrix. Note that no protocol was able to remove chondrocytes from their lacunae. 
Second set of decellularization protocols (LED based methods) - Histology assessment

The cartilaginous tissue submitted to LED irradiation with $475 \mathrm{~nm}$ and630nm wavelength, with a dose of $15 \mathrm{~J} / \mathrm{cm}^{2}$ presented several lacunae without cells, although there is remaining nuclear material in such decellularized cartilaginous tissue (Figures 5 and 6).
$8 \mathrm{~h}$
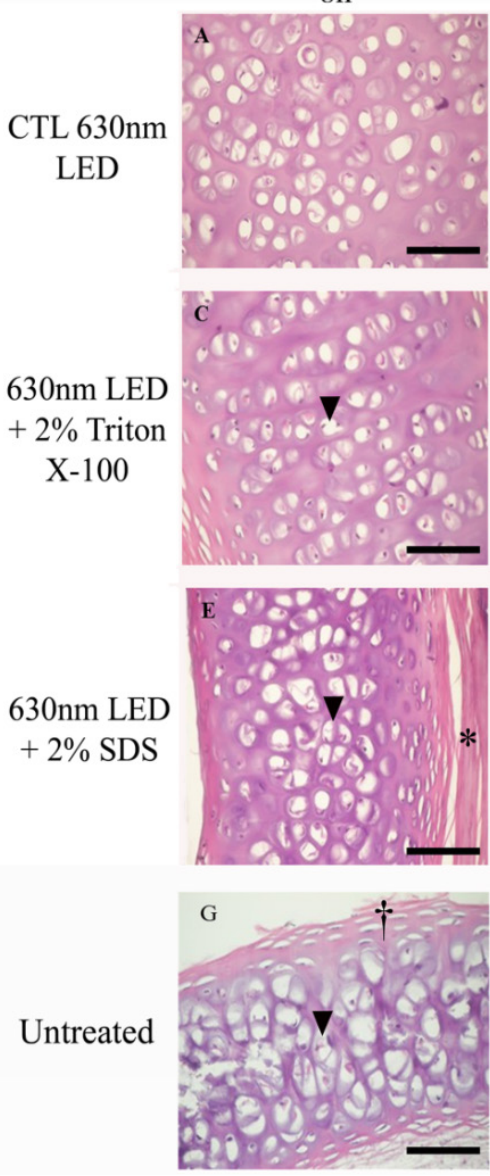

$24 \mathrm{~h}$
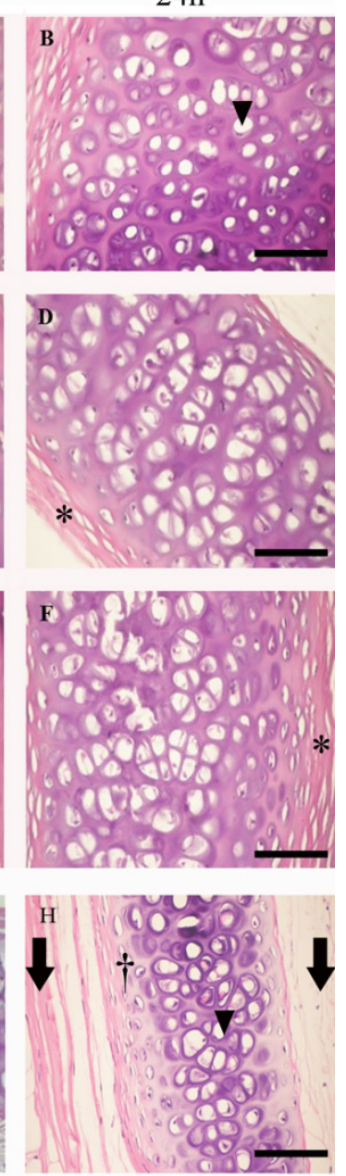

FIGURE 5 - Histological sections of the tracheal rings after the second set of decellularization protocols. The tracheas were submitted to the decellularization protocols, fixed in $10 \%$ buffered formaldehyde, embedded in Paraplast ${ }^{\mathrm{TM}}$, sectioned at a microtome and stained with H\&E. All sections were analyzed at x20 zoom. (A) Tracheal segment treated with $630 \mathrm{~nm}$ LED during $8 \mathrm{~h}$. (B) Tracheal segment treated with $630 \mathrm{~nm}$ LED during 24h. (C) Tracheal segment treated with 630nm LED + $2 \%$ triton $\times 100$ during $8 \mathrm{~h}$. (D) Tracheal segment treated with $630 \mathrm{~nm}$ LED $+2 \%$ triton x100 during $24 \mathrm{~h}$. (E) Tracheal segment treated with $630 \mathrm{~nm}$ LED $+2 \%$ SDS during $8 \mathrm{~h}$. (F) Tracheal segment treated with $630 \mathrm{~nm}$ LED $+2 \%$ SDS during $24 \mathrm{~h}$. (G) Untreated tracheal segment were submitted to agitation in basal solutions only during $8 \mathrm{~h}$. (H) Untreated tracheal segment were submitted to agitation in basal solutions only during 24h. All scale bars $=100 \mu \mathrm{m}$. Morphological aspects: $(*)$ Perichondrial area after decellularization. Note that the decellularization protocols remove all nuclei in this area. ( $\dagger$ Cellular perichondrium of the control trachea. Note the normal morphological aspects of the perichondrium. $(\downarrow)$ Fibrous perichondrium of the control trachea. Note the presence of fibroblasts nuclei and well-organized and thick type I collagen fibers. ( $\boldsymbol{\nabla})$ Hyaline cartilage area with the presence of remaining nuclei due to dense extracellular matrix. Note that no protocol was able to remove chondrocytes from their lacunae.

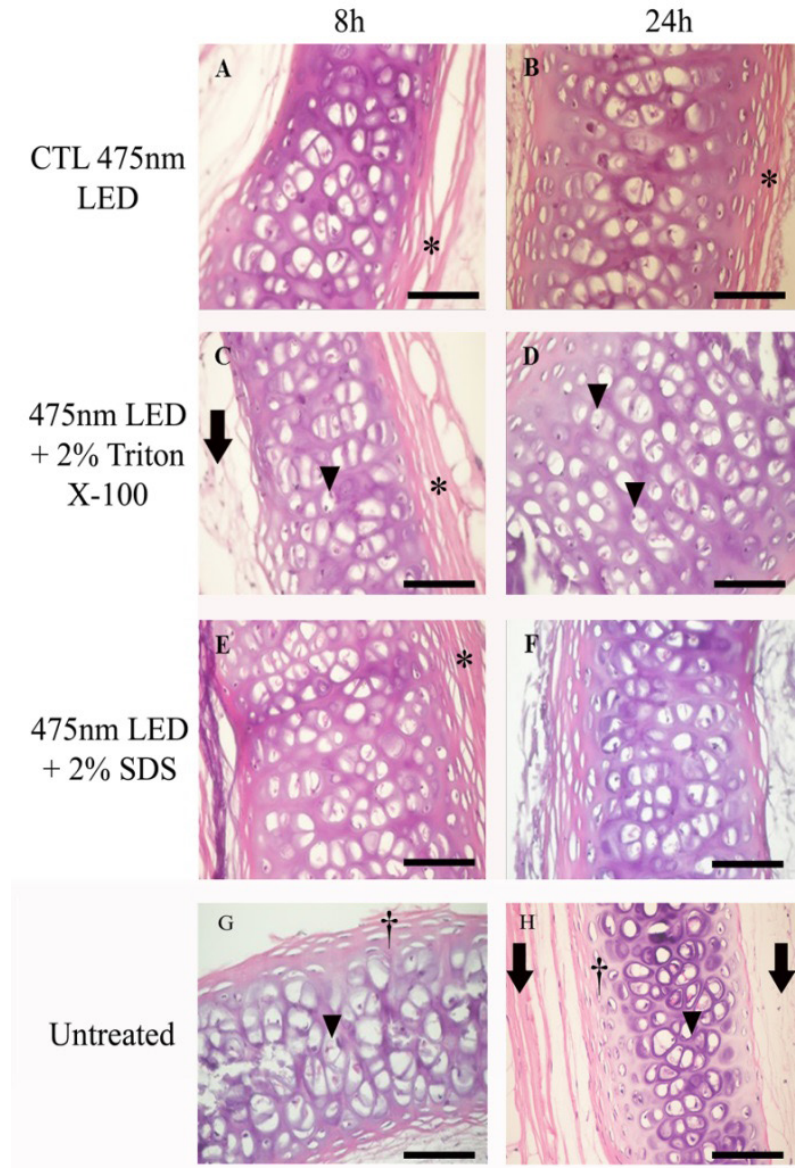

FIGURE 6 - Histological sections of the tracheal rings after the second set of decellularization protocols. The tracheas were submitted to the decellularization protocols, fixed in $10 \%$ buffered formaldehyde, embedded in Paraplast ${ }^{\mathrm{TM}}$, sectioned at a microtome and stained with H\&E. All sections were analyzed at x20 zoom. (A) Tracheal segment treated with $475 \mathrm{~nm}$ LED during $8 \mathrm{~h}$. (B) Tracheal segment treated with $475 \mathrm{~nm}$ LED during 24h. (C) Tracheal segment treated with 475nm LED + $2 \%$ triton x100 during $8 \mathrm{~h}$. (D) Tracheal segment treated with 475nm LED $+2 \%$ triton $x 100$ during $24 \mathrm{~h}$. (E) Tracheal segment treated with $475 \mathrm{~nm}$ LED $+2 \%$ SDS during $8 \mathrm{~h}$. (F) Tracheal segment treated with $475 \mathrm{~nm}$ LED $+2 \%$ SDS during $24 \mathrm{~h}$. (G) Untreated tracheal segment were submitted to agitation in basal solutions only during $8 \mathrm{~h}$. (H) Untreated tracheal segment were submitted to agitation in basal solutions only during $24 \mathrm{~h}$. All scale bars $=100 \mu \mathrm{m}$. Morphological aspects: $(*)$ Perichondrial area after decellularization. Note that the decellularization protocols remove all nuclei in this area. ( $\dagger$ ) Cellular perichondrium of the control trachea. Note the normal morphological aspects of the perichondrium. $(\downarrow)$ Fibrous perichondrium. Note the presence of fibroblasts nuclei and well-organized and thick type I collagen fibers on the untreated trachea and remaining nuclei only at the triton treated trachea. $(\boldsymbol{\nabla})$ Hyaline cartilage area with the presence of remaining nuclei due to dense extracellular matrix. Note that no protocol was able to remove chondrocytes from their lacunae.

\section{Discussion}

Regarding the first set of protocols, our findings does not corroborate with Elder et al. ${ }^{13}$ when they describe the action of the SDS and Triton x100 detergents as an effective process of decellularizing articular cartilage ${ }^{13}$ with complete lyses of 
the chondrocyte nuclear membranes and glycosaminoglycans removal; however, they applied the decellularization protocols on tissue engineered constructed cartilage that share the same remaining extracellular matrix tensile properties of a starting immature bovine cartilage (10-15\% of adult tissue). Therefore, their protocols may not have the same positive results if applied to native cartilage, which have much higher glycosaminoglycans and collagen content. Moreover, it was possible to verify that using the enzymes in the employed concentrations does not contribute in the decellularization protocols. To overcome this, an increase in the amount of nucleases could cause better results ${ }^{13}$. Specific literature, though, indicates that high amounts of enzymes should be used in order to get satisfactory results ${ }^{1}$.

It was previously reported that the employment of SDS causes some destruction of the cartilage tissue, due to the fact that SDS is an ionic detergent, which is efficient in the solubilization of cytoplasmatic and nuclear cell membranes, tends to denature protein by disrupting the protein-protein interactions, can remove glycosaminoglycans content, and collagen ${ }^{11,26}$. The nonionic detergents, like triton $\mathrm{x} 100$, act more mildly on the tissue structures and have the disruption of lipidlipid and lipid-protein interactions as a mechanism of action ${ }^{11}$. They do not alter the functional conformation since the proteinprotein interactions of the tissue remain intact ${ }^{11}$. Triton $\mathrm{x} 100$ is less harmful to glycosaminoglycans when compared to the other decellularization agents ${ }^{26,27}$. In our experiments, the apparent destruction of the remaining extracellular matrix seen at Figure 4 $(\mathrm{C}, \mathrm{E}, \mathrm{F})$ are not due to the detergent exposure, but a histological processing artifact.

It was not before the early 1980s that the effects of the electromagnetic radiation in molecular and cellular levels started being investigated ${ }^{28}$. Scientific papers conducted with LASER during the 1980s paved the foundations for the understanding of the molecular mechanisms concerning the effects of the interaction of light with biological tissues ${ }^{28}$.

Several in vitro studies described the effects of Laser and low-intensity LED on the biological tissues reporting an increase in the rates of cell proliferation and synthesis of mRNA and DNA, and an increase in the activation of the mitochondrial functional through structural changes. Consequently, the ATP synthesis also increases ${ }^{19}$, and so does the variation of the intra and extracellular $\mathrm{pH}$, the metabolism acceleration ${ }^{29}$, and the rate of epithelial cell proliferation ${ }^{30}$, which causes biophysical changes that may lead to an increased rate of exchanges in the cell membrane ${ }^{31}$.
More recent in vitro studies show that the action of low-intensity Laser can also be applied to repair and regenerate cartilages due to the biostimulation in the production of the cartilage matrix ${ }^{32}$. As well as that, they show that the interactions of the electromagnetic waves with the biological tissue cause the cells to warm up a little, including their mitochondrial membrane, leading to oxidative stress and triggering biochemical reactions that speed up the metabolism by increasing oxygen consumption ${ }^{32}$. A cell is usually able to overcome the effects of stress provided that the disturbances of the redox balance are small, restoring normal intracellular balance with positive stimulatory effects on the cells; largerscale disturbances, however, may be lethal to the cells ${ }^{17-19}$. In this sense, we hypothesized that a higher dose, like the dose chosen for this research $\left(15 \mathrm{~J} / \mathrm{cm}^{2}\right)$, could induce cell death, and consequently to contribute to the decellularization process.

Literature shows that irradiation with $630 \mathrm{~nm}+/-$ $20 \mathrm{~nm}$ LED with doses lower than $10 \mathrm{~J} / \mathrm{cm}^{2}$ stimulates cell proliferation ${ }^{33,34}$. However, higher doses than $10 \mathrm{~J} / \mathrm{cm}^{2}$ were used to induce cell death, as demonstrated by Karu. ${ }^{19}$ Some work described that the tissues irradiated with $475 \mathrm{~nm}+/-20 \mathrm{~nm}$ LED with doses higher than $10 \mathrm{~J} / \mathrm{cm}^{2}$ also causes cell damage ${ }^{33,34}$. Our findings confirm such results, which makes this protocol a new biotechnological method efficient in decellularizing natural scaffolds. The presence of chondrocytes could be tolerated during the matrix remodelling and scaffold recellularization with the cells from the receptor animals ${ }^{35}$.

\section{Conclusion}

The light-emitting diode is a promising tool for decellularization of soft tissues.

\section{References}

1. Macchiarini P,Jungebluth P,Go T,Asnagui MA,Rees LE, Cogan TA, Dodson A, Martorell J, Bellini S, Parnigotto PP, Dickinson SC, Hollander AP, Mantero S, Conconi MT, Birchal MA. Clinical transplantation of a tissue-engineered airway. Lancet. 2008 Dec 13;372(9655):2023-30. doi: 10.1016/S0140-6736(08)61598-6.

2. Jungebluth P, Go T, Asnaghi A, Bellini S, Martorell J, Calore C,Urbani L, Ostertag H, Mantero S, Conconi MT, Macchiarini P. Structural and morphologic evaluation of a novel detergent-enzymatic tissueengineered tracheal tubular matrix. J Thorac Cardiovasc Surg. 2009 Sep;138(3):586-93. doi: 10.1016/j.jtcvs.2008.09.085.

3. Weidenbecher M, Tucker HM, Awadallah A, Dennis JE. Fabrication of a neotrachea using engineered cartilage. Laryngoscope. 2008 Apr;118(4):593-8. doi: 10.1097/MLG.0b013e318161f9f8.

4. Baiguera S, Damasceno KL, Macchiarini P. Detergent-enzymatic method for bioengineering human airways. In: Uygun $\mathrm{K}$, Lee 
CY, editors. Methods in bioengineering: organ preservation and reengineering. Massachusetts: Artech House; 2011. p.193-210.

5. Elliott MJ, De Coppi P, Speggiorin S, Roebuck D, Butler CR, Samuel E, Crowley C, McLaren C, Fierens A, Vondrys D, Cochrane L, Jephson C, Janes S, Beaumont NJ, Cogan T, Bader A, Seifalian AM, Hsuan JJ, Lowdell MW, Bircall MA. Stem-cell-based, tissue engineered tracheal replacement in a child: a 2-year follow-up study. Lancet. 2012 Sep 15;380(9846):994-1000. doi: 10.1016/S01406736(12)60737-5.

6. Sung SW, Won T. Effects of basic fibroblast growth factor on early revascularization andepithelial regeneration in rabbit tracheal orthotopic transplantation. Eur J Cardiothorac Surg. 2001 Jan;19(1):14-8. doi: 10.1016/S1010-7940(00)00624-2.

7. Seguin A, Radu D, Holder-Espinasse M, Bruneval P, FialaireLegendre A, Duterque-Coquillaud M, Carpentier A, Martino DE. Tracheal replacement with cryopreserved, decellularized, or glutaraldehyde-treated aortic allografts. Ann Thorac Surg. 2009 Mar;87(3):861-7. doi: 10.1016/j.athoracsur.2008.11.038.

8. Martinod E, Seguin A, Holder-Espinasse M, Kambouchner M,Duterque-Coquillaud M, Azorin JF, Carpentier AF. Tracheal regeneration following tracheal replacement with an allogenic aorta. Ann Thorac Surg. 2005 Mar;79(3):942-8. doi:10.1016/j. athoracsur.2004.08.035.

9. Yamashita M, Kanemaru S, Hirano S, Magrufov A, Tamaki H, Tamura Y.Tracheal regeneration after partial resection: a tissue engineering approach. Laryngoscope. 2007 Mar;117(3):497-502. doi: 10.1097/MLG.0b013e31802e223d.

10. Birchall M, Macchiarini P. Airway transplantation: a debate worth having? Transplantation. 2008 Apr 27;85(8):1075-80. doi: 10.1097/ TP.0b013e31816a10e4

11. Gilbert TW, Sellaro TL, Badylak SF. Decellularization of tissues and organs. Biomaterials. 2006 Jul;27(19):3675-83. doi: 10.1016/j. biomaterials.2006.02.014.

12. Moroz A, Bittencourt RA, Almeida RP, Felisbino SL, Deffune E. Platelet lysate 3D scaffold supports mesenchymal stem cell chondrogenesis:Animprovedapproachincartilagetissueengineering. Platelets. 2013;24(3):219-25. doi: 10.3109/09537104.2012.686255.

13. Elder BD, Eleswarapu SV, Athanasiou KA. Extraction techniques for the decellularization of tissue engineered articular cartilage constructs. Biomaterials. 2009 Aug;30(22):3749-56. doi: 10.1016/j. biomaterials.2009.03.050.

14. Bagnato VS. Os fundamentos da luz laser. Fis Esc. 2001;2: 4-9.

15. Bagnato VS. Inventor. The use of LEDs (light emitting diodes) for biostimulation therapy. BRPI0200200-0. 23 Jan 2002.

16. Bagnato VS. Laser and it's applications in science and technology. São Paulo: Department of phisics book store, 2008.

17. Song J, Gao T, Ye M, Bi H, Liu G. The photocytotoxicity of different lights on mammalian cells in interior lighting system. J Photochem Photobiol B. 2012 Dec 5;117:13-8. doi: 10.1016/j. jphotobiol.2012.08.007.

18. Lubart R, Friedman H, Peled I, Grossman N. Light effect on fibroblast proliferation. Laser Ther.1993 Jan;5:55-7.

19. Karu T. Photobiology of low-power laser effects. Health Phys. 1989 May;56(5):691-704.

20. Bittencourt RAC, Pereira HR, Felisbino SL, Ferreira RR, Guilherme GRB, Moroz A, Deffune E. Chondrocyte cultures in tridimensional scaffold: alginate hydrogel. Acta Ortop Bras. 2009 Mar 17(4):2426. doi: 10.1590/S1413-78522009000400011.

21. Moroz A, Bittencourt RAC, Felisbino SL, Pereira HR, RossiFerreira R, Deffune E. Platelet gel: 3D scaffold for cell culture. Acta Ortop Bras. 2009 Jan;17(2):43-5. doi: 10.1590/S141378522009000200008

22. Wu W, Cheng X, Zhao Y, Chen F, Feng X, Mao T. Tissue engineering of trachea-like cartilage grafts by using chondrocyte macroaggregate: experimental study in rabbits. Artif Organs. 2007 Nov;31(11):826-34. doi: 10.1111/j.1525-1594.2007.00474.x.

23. Roh JL, Kim DH, Rha KS, Sung MW, Kim KH, Park CI. Benefits and risks of mitomycin use in the traumatized tracheal mucosa. Otolaryngol Head Neck Surg. 2007 Mar;136(3):459-63. doi: 10.1016/j.otohns.2006.09.012.

24. Nakagishi Y, Morimoto Y, Fujita M, Ozeki Y, Maehara T, Kikuchi M. Rabbit model of airway stenosis induced by scraping of the tracheal mucosa. Laryngoscope. 2005 Jun;115(6):1087-92. doi: 10.1097/01.MLG.0000163105.86513.6D.

25. Paiva FP, Maffili VV, Santos ACS. Course on laboratory animal handling. Brasília: Health ministry, Oswaldo Cruz Foundation, Gonçalo Muniz Research Center. 2005.

26. Vavken P, Joshi S, Murray MM. Triton-X is most effective among three decellularization agents for ACL tissue engineering. J Orthop Res. 2009 Dec;27(12):1612-8. doi: 10.1002/jor.20932.

27. Baptista PM, Orlando G, Mirmalek-Sani SH, Siddiqui M, Atala A, Soker S. Whole organ decellularization - a tool for bioscaffold fabrication and organ bioengineering. Conf Proc IEEE Eng Med Biol Soc. 2009;2009:6526-9. doi: 10.1109/IEMBS.2009.5333145.

28. Karu TI. Photobiological fundamentals of low-power laser therapy. IEEE J Quantum Electronics. 1987 Oct;23:1703-17. doi: 10.1109/ JQE.1987.1073236.

29. Dortbudak O, Haas R, Berhart T, Matejka M. Photodynamic therapy for bacterial reduction of periodontal microorganisms. J Oral Laser Appl. 2001;1:115-8.

30. Steinlechner CWB,Dyson M. The effects of low level laser therapy on the proliferation of keratinocytes. Laser Therapy. 1993;5:65-73.

31. Wong BJF, Milner TE, Kim HK, Telenkov S, Chew CF, Sobol EN, Nelson JS.Characterization of temperature-dependent biophysical properties during laser mediated cartilage reshaping. IEEE Select Topics Quantum Electron. 1999;5:1095-102. doi:10.1109/2944.796335.

32. Scheller EE, Rohde E, Minet O, Muller G, Bindig U. Calculations regarding cell metabolism stimulation using photons in the visible wavelength range. Laser Phys Lett. 2008 Sep;5(1):70-4. doi: 10.1002/lapl.200710087.

33. Karu TI. Low power-laser therapy. In: Dinh T. Biomed photon handbook. Boca Raton: CRC Press; 2003.

34. Karu TI, Pyatibrat LV, Kolyakov SF, Afanasyeva NI. Absorption measurements of a cell monolayer relevant to phototherapy: reduction of cytochrome $\mathrm{c}$ oxidase under near IR radiation. J Photochem Photobiol B. 2005 Nov 1;81(2):98-106. doi: 10.1016/j. jphotobiol.2005.07.002.

35. Partington L, Mordan NJ, Mason C, Knowles JC, Kim H-W, Lowdell MW, Birchall MA, Wall IB. Biochemical changes caused by decellularization may compromise mechanical integrity of tracheal scaffolds. Acta Biomater. 2013 Feb;9(2):5251-61. doi: 10.1016/j.actbio.2012.10.004.

\section{Acknowledgements}

To the staff of the Cell Engineering Laboratory, Botucatu Medical School (UNESP), and the technical assistance of Ednélson Henrique Bianchi, Carlos Roberto Gonçalvez Lima, and José Lucas de Carvalho. 
Evaristo TC et al.

\section{Correspondence:}

Elenice Deffune

Centro de Transfusão de Sangue

Departamento de Urologia, Faculdade de Medicina - UNESP

Distrito de Rubião Júnior, $\mathrm{s} / \mathrm{n}$

18618-970 Botucatu - SP Brasil

Tel.: (55 14)3811-6041 Ramal 234

Fax: (55 14)3811-6041 Ramal 205

ed12@fmb.unesp.br

Received: Mar 26, 2014

Review: May 27, 2014

Accepted: Jun 24, 2014

Conflict of interest: none

Financial source: Sao Paulo Research Foundation (FAPESP, 10/50155-2)

${ }^{1}$ Research performed at Cellular Engineering Laboratory of Blood Transfusion Center and Experimental Surgery Laboratory, Blood Transfusion and Hemotherapy Discipline, Urology Department, Medical School, Paulista State University (UNESP), Botucatu-SP, Brazil. Part of Master degree thesis, Postgraduate Program in Research and Development Medical Biotechnology, UNESP. Tutor: Profa. Elenice Deffune. 